\title{
Effects of different oocyte retrieval and in vitro maturation systems on bovine embryo development and quality
}

\author{
Sandra Milena Bernal Ulloa 2,3,4, Julia Heinzmann ${ }^{2}$, Doris Herrmann ${ }^{2}$, Bernd Timmermann ${ }^{5}$, \\ Ulrich Baulain ${ }^{2}$, Rudolf Großfeld ${ }^{6}$, Mike Diederich $^{7}$, Andrea Lucas-Hahn ${ }^{2}$ and Heiner Niemann ${ }^{1,2}$ \\ Institute of Farm Animal Genetics, Biotechnology, Friedrich-Loeffler-Institut (FLI), Mariensee, Germany; Facultad de Ciencias \\ Agropecuarias, Universidad de Ciencias Aplicadas y Ambientales, Bogotá, Colombia; Adaptation Physiology Group, \\ Wageningen, Wageningen University, The Netherlands; Max Planck Institute for Molecular Genetics, Berlin, Germany; \\ Minitube $\mathrm{GmbH}$, Tiefenbach, Germany; and Weser-Ems-Union eG, Rodenkirchen, Germany
}

Date submitted: 26.07.2013. Date revised: 02.10.2013. Date accepted: 04.10.2013

\section{Summary}

Cyclic adenosine monophosphate (cAMP) modulators have been used to avoid spontaneous oocyte maturation and concomitantly improve oocyte developmental competence. The current work evaluated the effects of the addition of cAMP modulators forskolin, 3-isobutyl-1-methylxanthine (IBMX) and cilostamide during in vitro maturation on the quality and yields of blastocysts. The following experimental groups were evaluated: (i) slicing or (ii) aspiration and maturation in tissue culture medium (TCM)199 for $24 \mathrm{~h}$ (TCM24slicing and TCM24aspiration, respectively), (iii) aspiration and maturation in the presence of cAMP modulators for $30 \mathrm{~h}$ (cAMP30aspiration) and in vivo-produced blastocysts. In vitro-matured oocytes were fertilized and presumptive zygotes were cultured in vitro to assess embryo development. Cleavage, blastocyst formation, blastocyst cell number, mRNA abundance of selected genes and global methylation profiles were evaluated. Blastocyst rate/zygotes for the TCM24aspiration protocol was improved $(32.2 \pm 2.1 \%)$ compared with TCM24slicing and cAMP30aspiration $(23.4 \pm 1.2 \%$ and $23.3 \pm 2.0 \%$, respectively, $P<0.05)$. No statistical differences were found for blastocyst cell numbers. The mRNA expression for the EGR1 gene was down-regulated eight-fold in blastocysts that had been produced in vitro compared with their in vivo counterparts. Gene expression profiles for IGF2R, SLC2A8, COX2, DNMT3B and PCK2 did not differ among experimental groups. Bovine testis satellite I and Bos taurus alpha satellite methylation profiles from cAMP30aspiration protocol-derived blastocysts were similar to patterns that were observed in their in vivo equivalents $(P>0.05)$, while those from the other groups were significantly elevated. It is concluded that retrieval, collection systems and addition of cAMP modulators can affect oocyte developmental competence, which is reflected not only in blastocyst rates but also in global DNA methylation and gene expression patterns.

Keywords: cAMP modulators, In vitro maturation, Oocyte competence, Preimplantation embryo

\footnotetext{
${ }^{1}$ All correspondence to: Heiner Niemann. Institute of Farm Animal Genetics, Biotechnology, Friedrich-Loeffler-Institut (FLI), Mariensee, Höltystraße 10, Mariensee, 31535 Neustadt, Germany. Tel: +49 5034871136. Fax: +49 5034871143. e-mail: heiner.niemann@fli.bund.de

${ }^{2}$ Institute of Farm Animal Genetics, Biotechnology, Friedrich-Loeffler-Institut (FLI), Mariensee, Neustadt, Germany.

${ }^{3}$ Facultad de Ciencias Agropecuarias, Universidad de Ciencias Aplicadas y Ambientales, Calle 222 No. 55-37, Bogotá, Colombia.

${ }^{4}$ Adaptation Physiology Group, Wageningen University, De Elst 1 (Building 122) 6708 WD Wageningen, The Netherlands. ${ }^{5}$ Max Planck Institute for Molecular Genetics, Ihnestraße 6373, 14195, Berlin, Germany.
}

\section{Introduction}

In modern cattle production, in vitro maturation (IVM) of oocytes is widely used as part of the in vitroproduction systems for bovine embryos. Recent figures have indicated that in 2011 there were 374,000 transfers that used in vitro-produced embryos (Stroud, 2012). Nevertheless, numerous studies have found that IVM

\footnotetext{
${ }^{6}$ Minitube GmbH Hauptstrasse 41, Tiefenbach, Germany. ${ }^{7}$ Weser-Ems-Union eG, Aussenstelle Rodenkirchen, Bullenmutterstation, Mittenfelder Weg 11, 26935 Rodenkirchen, Germany.
} 
can be associated with changes in gene expression and methylation profiles that result in deterioration in the developmental competence of oocytes and early embryos (Wrenzycki et al., 2005a, 2007; Heinzmann et al., 2011; Diederich et al., 2012).

When IVM is performed, the oocyte is released mechanically from its antral follicle, this release in turn triggers meiotic resumption and results in maturation of the oocyte and arrest at metaphase II (Mehlmann, 2005; Zhang et al., 2010). This process has been designated 'spontaneous' or 'pseudo' maturation and has been attributed to the removal of inhibitory factors from the follicle rather than active processes (Pincus \& Enzmann, 1935; Tsafriri \& Pomerantz, 1986). Several suggestions have been made to improve IVM that included matching the IVM medium to requirements of the cumulus-oocyte complexes (COCs), inhibition or delay of spontaneous maturation and acquisition of oocyte capacitation. Delay or inhibition of spontaneous maturation has been employed successfully and several molecules have been applied to better simulate the physiological pathways of oocyte maturation.

Different biochemical pathways are involved in oocyte maturation, which culminates in cumulus expansion and cytoplasmic and nuclear maturation, reflected by acquisition of complete developmental competence (Tripathi et al., 2010). Cyclic adenosine monophosphate (cAMP) is critical for the maintenance of meiotic arrest in vivo. Elevated intra-oocyte levels of cAMP maintain oocytes in meiotic arrest by suppression of maturation promoting factor (MPF) and by stimulation of cAMP-dependent protein kinase A (PKA) [reviewed by Bilodeau-Goeseels (2011)]. The application of different approaches has been reported to increase cAMP content in oocytes and the surrounding cumulus cells during IVM. Albuz et al. (2010) reported that bovine COCs matured in the presence of cAMP modulators forskolin, 3-isobutyl1-methylxanthine (IBMX) or cilostamide, before and during extended IVM (simulated physiological oocyte maturation (SPOM)), should increased bovine embryo production and quality based on blastocyst cell numbers. However, to our knowledge, no reports have been published on the expression profile of selected genes and global DNA methylation status of SPOM-derived bovine blastocysts, which are important parameters of embryo quality assessment. The current work set out to characterize SPOMderived blastocysts in detail. Specifically, the effects of supplementation of the basic culture medium with forskolin, IBMX and cilostamide before and during extended IVM on the developmental potential of bovine COCs, mRNA abundance of genes related to cell physiology, methylation and imprinting, and also DNA methylation were studied in two satellite repeat sequences of bovine preimplantation embryos.

\section{Materials and methods}

The original SPOM method was performed in connection with aspiration of bovine ovarian follicles from slaughtered females (Albuz et al., 2010). The method of oocyte recovery used routinely in our laboratory is slicing of ovaries rather than aspiration, therefore slicing was used as a 'control' in the current work. We consider that slicing mimics the ovum pick-up clinical approach sufficiently well, in which follicular fluid is diluted during oocyte recovery. Experiments were designed that included oocytes retrieved either via aspiration or by slicing. Therefore, three different IVM protocols for bovine oocytes were used in the current study, and the developmental potential of the selected COCs as well as blastocyst quality were examined. The protocols varied in the method of oocyte retrieval (slicing and aspiration), addition of cAMP modulators and length of the IVM period of the COCs. In vivo-produced expanded blastocysts were used as a physiological standard for comparison with their counterparts produced in vitro. All media used in the different procedures of in vitro and in vivo blastocyst production were prepared in-house in accordance with the manufacturer's recommendations.

\section{Oocyte recovery}

Bovine ovaries from a local slaughterhouse were transported at $30^{\circ} \mathrm{C}$ in saline solution supplemented with $6 \mu \mathrm{g} / \mathrm{ml}$ penicillin G (AppliChem, Darmstadt, Germany) and $50 \mu \mathrm{g} / \mathrm{ml}$ streptomycin sulphate (AppliChem).

To obtain COCs, the ovaries were either submitted to aspiration or slicing. For aspiration, follicles $3-8 \mathrm{~mm}$ in diameter were punctured using $18 \mathrm{G} \times 1 \frac{1}{2}$ needles; follicular fluid that contained the oocytes was collected in sterile $50 \mathrm{ml}$ centrifuge tubes (Corning ${ }^{\circledR}$, New York, USA), connected to a vacuum pump that had been adjusted to a negative pressure of $100 \mathrm{mmHg}$ (VM AR5100, Cook, Queensland, Australia; Holker et al., 2005). Immediately after collection, COCs were examined under a stereomicroscope in undiluted follicular fluid to avoid a drop in cAMP levels.

Ovaries with follicles of 3-8 $\mathrm{mm}$ in diameter were sliced to release COCs, which were examined in Dulbecco's phosphate-buffered saline (PBS; AppliChem) supplemented with $2.2 \mathrm{IU} / \mathrm{ml}$ heparin (AppliChem), $1 \mathrm{mg} / \mathrm{ml}$ bovine serum albumin (BSA; Sigma-Aldrich), $6 \mu \mathrm{g} / \mathrm{ml}$ penicillin G (AppliChem) and $50 \mu \mathrm{g} / \mathrm{ml}$ streptomycin sulphate (AppliChem; Wrenzycki et al., 2001).

For both retrieval protocols, only COCs with homogeneous cytoplasm and at least three layers of cumulus cells were selected (categories I and II) for IVM (Looney et al., 1994, Goodhand et al., 1999). 


\section{In vitro maturation (IVM) protocols}

Standard IVM (TCM24slicing)

After slicing, oocytes were collected and maintained in tissue culture medium (TCM) 199 (TCM199, SigmaAldrich), enriched with $50 \mu \mathrm{g} / \mathrm{ml}$ gentamicin sulphate (Sigma-Aldrich), $0.2 \mathrm{mM}$ Na-pyruvate (SigmaAldrich), $4.2 \mathrm{mM} \mathrm{NaHCO}_{3}$ (Honeywell Riedel de Haën, Seelze, Germany) and $1 \mathrm{mg} / \mathrm{ml}$ BSA-FAF (Sigma-Aldrich; Eckert \& Niemann, 1995), here called TCM-air medium.

For IVM, selected COCs were washed three times in TCM199 that contained $0.2 \mathrm{mM}$ Na-pyruvate (SigmaAldrich), $25 \mathrm{mM} \mathrm{NaHCO}$ (Honeywell Riedel-de Haën), $50 \mu \mathrm{g} / \mathrm{ml}$ gentamycin (Sigma-Aldrich) and $1 \mathrm{mg} / \mathrm{ml}$ FAF-BSA (Sigma-Aldrich). This medium is termed TCM-culture in the present study. Groups of 15-20 COCs were incubated in $100 \mu \mathrm{l}$ TCM-culture drops under silicone oil that contained $10 \mathrm{UI} / \mathrm{ml}$ of equine chorionic gonadotropin (eCG) and $5 \mathrm{IU} / \mathrm{ml}$ of human chorionic gonadotropin (hCG; Suigonan ${ }^{\mathbb{B}}$, Intervet, Unterschleissheim, Germany; Heinzmann et al., 2011). Oocytes were incubated in a humidified atmosphere at $39^{\circ} \mathrm{C}, 5 \% \mathrm{CO}_{2}$ in air for $24 \mathrm{~h}$.

\section{TCM24aspiration (retrieval control)}

Following aspiration, COCs were collected in TCM-air medium and subsequently treated as described for the standard IVM protocol (TCM24slicing).

\section{Modified extended IVM system (cAMP30aspiration)}

For the cAMP30aspiration protocol, the selected COCs were maintained in TCM-air medium additionally supplemented with $500 \mu \mathrm{M}$ 3-isobutylmethylxanthine (IBMX, Sigma-Aldrich) and $100 \mu \mathrm{M}$ forskolin (FSK, Sigma-Aldrich) to ensure consistently high cAMP levels (Albuz et al., 2010). The COCs were washed three times in TCM-air that contained FSK and IBMX and were then cultured prior to IVM (pre-IVM) for $2 \mathrm{~h}$ in groups of 15-20 COCs in $100 \mu \mathrm{l}$ drops under silicone oil at $39^{\circ} \mathrm{C}$ in air.

After the pre-IVM phase, COCs were washed three times in TCM-culture medium that contained $20 \mu \mathrm{M}$ cilostamide (Sigma-Aldrich), and matured in vitro in $100 \mu l$ drops of TCM-culture medium, supplemented with $20 \mu \mathrm{M}$ cilostamide and Suigonan ${ }^{\circledR}$ in a humidified atmosphere at $39^{\circ} \mathrm{C}, 5 \% \mathrm{CO}_{2}$ in air for $30 \mathrm{~h}$.

\section{Evaluation of in vitro maturation success}

Cumulus cells were removed from subsets of COCs for every protocol by incubation in PBS supplemented with $0.1 \%$ hyaluronidase (Sigma-Aldrich) and $1 \mathrm{mg} / \mathrm{ml} \mathrm{BSA} \mathrm{(Fraction} \mathrm{V,} \mathrm{Sigma-Aldrich)} \mathrm{for} 5 \mathrm{~min}$ at $38^{\circ} \mathrm{C}$ and subsequent centrifugation for $5 \mathrm{~min}$ at $1400 \mathrm{rpm}$. Any remaining cumulus cells were removed by gentle pipetting. Oocytes were washed in TCM- air and evaluated under a stereomicroscope. Meiotic resumption was determined by the presence of the first polar body after IVM.

\section{In vitro fertilization (IVF) and culture (IVC)}

After maturation, COCs from the different protocols were processed in accordance with Heinzmann et al. (2011)). Oocytes were washed three times in fertilization medium (Fert-TALP; Parrish et al., 1986, 1988) that contained $6 \mathrm{mg} / \mathrm{ml}$ BSA (fraction V, SigmaAldrich), $0.05 \mathrm{mg} / \mathrm{ml}$ gentamicin (Sigma-Aldrich) and $0.028 \mathrm{mg} / \mathrm{ml} \mathrm{Na-pyruvate} \mathrm{(Sigma-Aldrich),} \mathrm{and}$ transferred into $100 \mu \mathrm{l}$ drops under silicone oil of $100 \mu \mathrm{l}$ of Fert-TALP enriched with $10 \mu \mathrm{M}$ hypotaurine (Sigma-Aldrich), $0.1 \mathrm{IU} / \mathrm{ml}$ heparin (AppliChem), $1 \mu \mathrm{M}$ epinephrine (Sigma-Aldrich). Frozen-thawed sperm from one bull with proven performance in IVF was used. Motile spermatozoa were obtained by centrifugation of thawed sperm $\left(30^{\circ} \mathrm{C}, 2 \mathrm{~min}\right)$ in $1 \mathrm{ml}$ of $90 \%$ Bovipure $^{\mathrm{TM}}$ (Labotect, Göttingen, Germany) at $300 \mathrm{~g}$ for $10 \mathrm{~min}$. Spermatozoa were washed twice using Fert-TALP and centrifuged at $400 \mathrm{~g}$ for $3 \mathrm{~min}$. Spermatozoa were added to reach a final concentration of $1 \times 10^{6}$ cells/ $\mathrm{ml}$ and co-incubated with COCs for $19 \mathrm{~h}$ for the TCM24 protocols and $24 \mathrm{~h}$ for the COCs submitted to the CAMP30aspiration protocol, in a humidified atmosphere of $5 \% \mathrm{CO}_{2}$ in air at $39^{\circ} \mathrm{C}$. Immediately after fertilization, presumptive zygotes from all protocols were denuded by vortexing for $5 \mathrm{~min}$ in TCM-air medium. Completely denuded zygotes were washed twice in synthetic oviductal fluid (SOF) medium enriched with $4 \mathrm{mg} / \mathrm{ml}$ of BSA-FAF (SigmaAldrich; Wrenzycki et al., 2001; Heinzmann et al., 2011). Groups of five zygotes were cultured in $30 \mu$ l droplets of SOF under silicone oil at $39^{\circ} \mathrm{C}, 5 \% \mathrm{CO}_{2}$ and $5 \% \mathrm{O}_{2}$. Post-fertilization, embryo development was evaluated for cleavage (day 2) and blastocyst formation (day 8).

Expanded blastocysts on days 7 and 8 were either directly subjected to differential staining to assess cell numbers or frozen at $-80^{\circ} \mathrm{C}$ in PBS that contained $0.1 \%$ polyvinyl alcohol (PVA; PBS-PVA) in pools of three for gene expression analysis and pools of five for methylation analysis.

\section{In vivo production of embryos}

Holstein Friesian cows from the experimental herds of the Institute of Farm Animal Genetics in Mariensee (Germany) were superovulated using a single dose of 2500-3000 UI eCG (Intergonan ${ }^{\circledR}$; Intervet, Tönisvorst, Germany). A single dose of cloprostenol was administered $48 \mathrm{~h}$ after eCG ( $3 \mathrm{ml}$; Estrumate ${ }^{\circledR}$, Essex, Munich, Germany). Two artificial inseminations were performed, with sperm from the same bull used for IVF, $48 \mathrm{~h}$ after cloprostenol injection with a $12 \mathrm{~h}$ interval. Embryos were recovered from the uterine 
horns by non-surgical means on days 7 and 8 as described by Bungartz \& Niemann (1994). Dulbecco's PBS medium (AppliChem) supplemented with 1\% fetal calf serum (FCS; Invitrogen, Karlsruhe, Germany) was used for uterine flushing. Expanded blastocysts were frozen in groups of three for gene expression analysis and groups of five for methylation analyses in accordance with the protocol for in vitro-produced embryos. Additional blastocysts were processed for cell number counting by differential staining.

\section{Differential staining}

Cell numbers of the inner cell mass and trophectoderm from in vitro- and in vivo-derived expanded blastocysts were counted using a protocol described by Thouas et al. (2001), with minor modifications. Briefly, expanded blastocysts were washed in PBS-PVA and subsequently permeated and stained by incubation in PBS without $\mathrm{Ca}$ and $\mathrm{Mg}$ and containing $0.25 \%$ Triton X-100 (Packard Instruments Company, USA) and $0.2 \mathrm{mg} / \mathrm{ml}$ propidium iodide (Sigma, Munich Germany) for $30 \mathrm{~s}$. Thereafter, the embryos were washed twice in PBS-PVA and placed for $4 \mathrm{~min}$ in PBS that contained bisbenzimide (Hoechst 33258, Sigma, Munich Germany) dissolved in $4 \%$ formaldehyde (Honeywell Riedel de Haën, Seelze, Germany) for a final working concentration of $0.026 \mathrm{mg} / \mathrm{ml}$. The stained embryos were mounted on microscope slides in a small drop of glycerol (Carl Roth $\mathrm{GmbH}$, Karlsruhe, Germany). In order to determine the number and type of cells, the embryos were examined immediately under a fluorescence microscope (Olympus BX60F, Tokyo, Japan) at $\times 400$ magnification equipped with an ultraviolet filter and an attached digital camera (Olympus DP71). The trophectoderm (TE) nuclei appeared red and the inner cell mass (ICM) nuclei were blue.

\section{Determination of the relative mRNA abundance of developmentally important genes}

The relative abundance of selected genes was determined in expanded blastocysts using semi-quantitative real-time reverse transcription polymerase chain reaction (qRT-PCR). Analysed genes included the imprinted gene insulin-like growth factor 2 receptor (IGF2R), DNA methyltransferase 3b (DNMT3b), solute carrier family 2 (facilitated glucose transporter) member 8 (SLC2A8), prostaglandin $\mathrm{G} / \mathrm{H}$ synthase-2 (COX2), mitochondrial phosphoenolpyruvate carboxykinase 2 (PCK2) and early growth response 1 (EGR1). Pools of three blastocysts from four sources (TCM24slicing, TCM24aspiration, cAMP30aspiration and in vivo) were submitted to $\operatorname{poly}(\mathrm{A})^{+}$mRNA extraction using the Dynabeads ${ }^{\circledR}$ mRNA DIRECT ${ }^{\mathrm{TM}}$ kit (Invitrogen, Carlsbad, CA, USA; Niemann et al., 2010; Heinzmann et al., 2011). Lysis of the cells was performed using $40 \mu \mathrm{l}$ lysis binding buffer (100 mM Tris$\mathrm{HCl} \mathrm{pH}$ 8.0, $500 \mathrm{mM} \mathrm{LiCl}, 10 \mathrm{mM}$ EDTA, 1\% lithium dodecyl sulphate, $5 \mathrm{mM}$ dithiothreitol) and incubation for $10 \mathrm{~min}$ at room temperature, followed by addition of $1 \mathrm{pg} /$ reaction rabbit globin mRNA (BRL, Gaithersburg, MD, USA) as an external standard (Cheng et al., 1986) and $5 \mu$ l of prewashed Dynabeads ${ }^{\circledR}$ oligo(dT $)_{25}$. After a $15 \mathrm{~min}$ incubation at room temperature the poly(A) ${ }^{+}$RNAs bound to the beads were captured magnetically, washed in accordance with the manufacturer's instructions and resuspended in $11 \mu \mathrm{l}$ of water. Finally, the poly(A) ${ }^{+}$mRNAs were released from the beads by heating at $68^{\circ} \mathrm{C}$ for $2.5 \mathrm{~min}$ and were used immediately for reverse transcription. Reverse transcription reactions were performed in a total volume of $20 \mu \mathrm{l}$ that contained $2 \mu l$ of $10 \times$ reaction buffer (Invitrogen), $10 \mathrm{mM}$ dNTPs solution (Amersham Biosciences, Piscataway, NJ, USA), $2.5 \mu \mathrm{M}$ random hexamer primers (Applied Biosystems, Darmstadt, Germany), $20 \mathrm{U} / \mu \mathrm{l}$ ribonuclease inhibitor RNasin ${ }^{\circledR}$ (Applied Biosystems), $50 \mathrm{U} / \mu \mathrm{l}$ murine leukemia virus reverse transcriptase $(\mathrm{MuLV}$, Applied Biosystems), the extracted RNA sample and water to $20 \mu l$. The reverse transcription reaction was performed in a thermocycler (MJ Research PTC-200) and the program used was $10 \mathrm{~min}$ at $25^{\circ} \mathrm{C}, 60 \mathrm{~min}$ at $42^{\circ} \mathrm{C}$, and $5 \mathrm{~min}$ at $99^{\circ} \mathrm{C}$.

After reverse transcription, the cDNA obtained was submitted to semi-quantitative real-time qRTPCR. The reactions were performed in 96-well optical reaction plates (Applied Biosystems, Carlsbad, California, USA; Niemann et al., 2010; Heinzmann et al., 2011). The final volume for the reaction in each well was $20 \mu \mathrm{l}$ that contained $10 \mu \mathrm{l}$ of $2 \times$ Power SYBR $^{\circledR}$ Green PCR Master Mix (Applied Biosystems), $0.8 \mu \mathrm{l}$ of $5 \mu \mathrm{M}$ forward and reverse specific primers, $6.4 \mu \mathrm{l}$ water and $2 \mu \mathrm{l}$ cDNA. The details of the primers for the genes under evaluation are shown in Table 1. Standard curves of mRNA from pooled blastocyst cDNA were performed for each gene to assess the relative amount of the target gene in each sample. Values were normalized to the signal from the exogenous standard (rabbit globin) for each sample. The qRT-PCR reactions were carried out in an ABI 7500 Fast Real-Time System cycler (Applied Biosystems). The program used was $10 \mathrm{~min}$ at $95^{\circ} \mathrm{C}$ followed by 40 cycles of $15 \mathrm{~s}$ at $95^{\circ} \mathrm{C}, 60 \mathrm{~s}$ at $60^{\circ} \mathrm{C}, 15 \mathrm{~s}$ at $95^{\circ} \mathrm{C}$ and $1 \mathrm{~min}$ at $60^{\circ} \mathrm{C}$ followed by a slow heating cycle to obtain the dissociation curves. Sequence Detection Software 1.3.1 was used to perform quantification.

\section{Analysis of DNA methylation}

The methylation status of the sequences of the bovine testis satellite I (BTS) and Bos taurus alpha satellite 


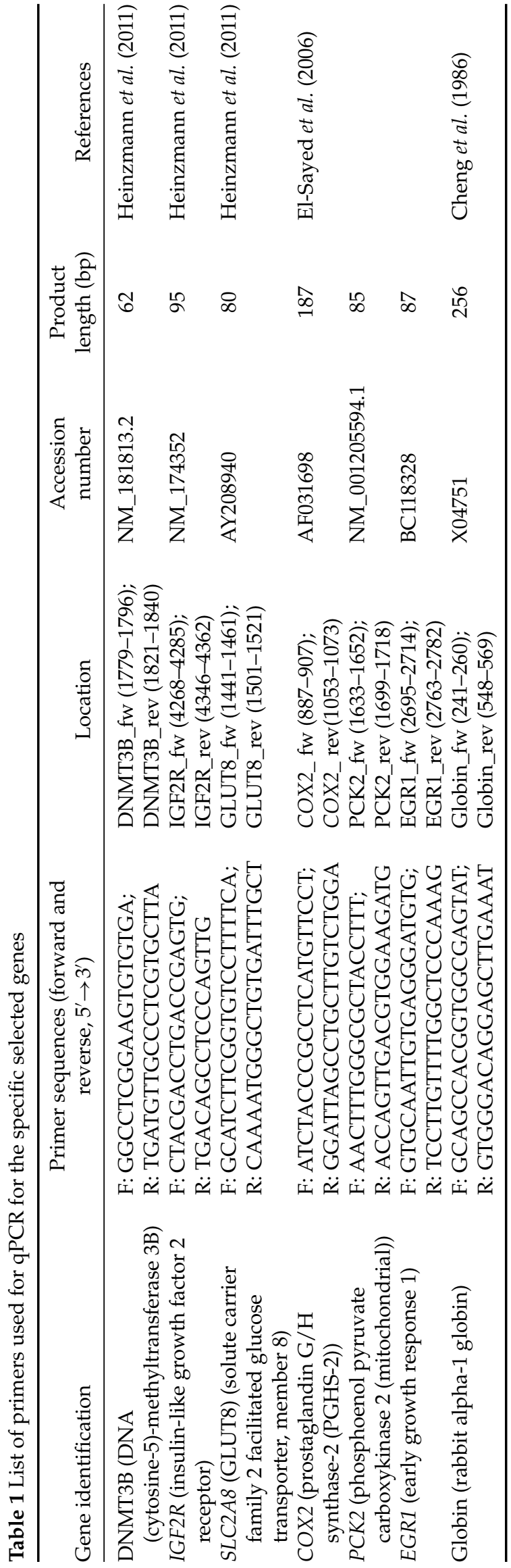

I $(B T \alpha S)$ was evaluated to gain an overview of the global methylation status of the bovine genome in preimplantation embryos derived from the SPOM system. In BTS, 12 highly conserved $\mathrm{CpG}$ sites were evaluated in a 211-bp fragment. For the BT $\alpha S$ sequence, a fragment of $154 \mathrm{bp}$ that contained nine CpG sites was analysed (Kang et al., 2001). Genomic DNA from pools of five blastocysts each from every IVM protocol and in vivo-produced blastocysts was subjected to bisulphite conversion using the EZ DNA Methylation-Direct ${ }^{\mathrm{TM}}$ Kit (Zymo Research, Freiburg, Germany) as described previously by Diederich et al. (2012). Briefly, blastocysts were digested with $13 \mu l 1 \mathrm{M}$ digestion buffer, $1 \mu \mathrm{l}$ proteinase $\mathrm{K}$, and $12 \mu \mathrm{l} \mathrm{H}_{2} \mathrm{O}$ at $50^{\circ} \mathrm{C}$ for $20 \mathrm{~min}$ and subsequently centrifuged for $5 \mathrm{~min}$ at $10,000 \mathrm{~g}$ in a bench top centrifuge. Bisulphite conversion was performed using the CT Conversion Reagent provided by the kit at $98^{\circ} \mathrm{C}$ for $8 \mathrm{~min}$ followed by $64^{\circ} \mathrm{C}$ for $3.5 \mathrm{~h}$ in a thermal cycler. The converted DNA was washed and cleaned using the Zymo-Spin ${ }^{\mathrm{TM}}$ IC Column and submitted to PCR amplification using satellite specific primers in accordance with Kang et al. (2005; Table 2). Subsequently, the PCR products were purified using the Wizard ${ }^{\circledR}$ SV Gel and PCR Clean-Up System (Promega, Mannheim, Germany). Fragments were ligated into the pGEM $^{\circledR}$-T-Easy Vector (Promega) and plasmids were transformed into Escherichia coli XL10 Gold ultracompetent cells (Stratagene, Santa Clara, CA, USA). Successful ligation and transformation was confirmed by screening of the obtained colonies by PCR using primers SP6 and T7 (Table 2) and positive clones were submitted to sequencing analysis using the same primers. Sequences were analysed using the BiQ Analyzer program (MPI for Informatics, Saarland, Germany; Bock et al., 2005). The sequences were compared with the specific genomic sequence from the bovine genome for each satellite. Clones with a conversion rate lower than $90 \%$ or with a high number of sequencing errors in the alignment were excluded from the analysis. The methylation status per treatment for each satellite was evaluated counting the total methylated $\mathrm{CpG}$ sites of the total number of analysed CpG.

\section{Statistical analysis}

Non-parametric one-way analysis of variance (ANOVA) was performed to evaluate gene expression and one-way ANOVA was implemented to analyse the number of cells, using JMP Statistical Discovery software $^{\mathrm{TM}}$ version 8.0. (SAS Institute Inc., Cary, NC, USA, 1989-2007). Maturation, blastocyst, cleavage and methylation rates were evaluated using the Glimmix procedure from SAS/STAT ${ }^{\circledR}$ software version 9.2. The experimental groups were always run in parallel. In 
Table 2 Primer sequences used for analysis of repeat sequences

\begin{tabular}{|c|c|c|c|c|}
\hline Repeat/binding site & $\begin{array}{c}\text { GenBank } \\
\text { accession no. }\end{array}$ & Primer sequences $\left(5^{\prime} \rightarrow 3^{\prime}\right)$ & $\begin{array}{l}\text { Fragment } \\
\text { size (bp) }\end{array}$ & References \\
\hline Bovine testis satellite I (BTS) & J00032.1 & $\begin{array}{l}\text { AATACCTCTAATTTCAAACT } \\
\text { TTTGTGAATGTAGTTAATA }\end{array}$ & 211 & Kang et al. (2005) \\
\hline $\begin{array}{l}\text { Bos taurus alpha } \\
\text { satellite I (BT } \alpha \text { S) } \\
\text { T7 } \\
\text { SP6 }\end{array}$ & AJ293510.1 & $\begin{array}{l}\text { GATGTTTTYGGGGAGAGAGG } \\
\text { CCRATCCCCTCTTAATAAAAACC } \\
\text { ACTCACTATAGGGCGAATTG } \\
\text { ATTTAGGTGACACTATAGAATACTC }\end{array}$ & 154 & Kang et al. (2005) \\
\hline
\end{tabular}

Table 3 Effect of oocyte retrieval method and maturation in vitro system on cleavage and blastocyst rates

\begin{tabular}{lcccc}
\hline Treatment & $\begin{array}{c}\text { Total } \\
\text { zygotes }(n)\end{array}$ & $\begin{array}{c}\text { Total blastocysts } \\
\text { day } 8(n)\end{array}$ & $\begin{array}{c}\text { 2-cell embryos } \\
\text { at day 2 }(\%)^{c}\end{array}$ & $\begin{array}{c}\text { Blastocysts/presumptive } \\
\text { zygotes }(\%)^{c}\end{array}$ \\
\hline TCM24slicing $^{d}$ & 1173 & 275 & $58.9 \pm 1.5^{b}$ & $23.4 \pm 1.2^{b}$ \\
TCM24aspiration $^{e}$ & 485 & 156 & $63.0 \pm 2.3^{a, b}$ & $32.2 \pm 2.1^{a}$ \\
cAMP30aspiration $^{f}$ & 476 & 111 & $70.1 \pm 2.4^{a}$ & $23.3 \pm 1.9^{b}$ \\
\hline
\end{tabular}

${ }^{a, b}$ Mean values followed by different superscript letters in the same column differ statistically among maturation systems $(P$ $<0.05)$. The column 'Blastocysts/presumptive zygote' includes all oocytes that were initially placed into culture.

${ }^{c}$ Data are expressed as mean \pm standard error of the mean (SEM). ${ }^{d} 19$ replicates. ${ }^{e} 10$ replicates. ${ }^{f} 12$ replicates.

Table 4 Effect of oocyte retrieval method and maturation in vitro system on oocyte meiosis resumption

\begin{tabular}{lccc}
\hline Treatment & Total $(n)$ & Metaphase II $(n)$ & ${\text { Maturation rates }(\%)^{b}}^{b}$ \\
\hline TCM24slicing $^{b}$ & 158 & 112 & $70.1 \pm 3.6$ \\
TCM24aspiration $^{b}$ & 84 & 67 & $79.8 \pm 4.3$ \\
cAMP30aspiration $^{a}$ & 98 & 73 & $74.5 \pm 4.4$ \\
\hline
\end{tabular}

${ }^{a}$ Data are expressed as mean \pm standard error of the mean (SEM). ${ }^{b}$ Three replicates were performed.

some cases there was not enough biological material to run all groups in one experimental set-up. This factor explains the different number of replicates for the various experimental groups in Table 3 and this difference was taken into account for the statistical analysis. For all tests statistical significance was set at $P<0.05$.

\section{Results}

\section{In vitro oocyte maturation and embryo production}

No statistical differences were found among the three groups of IVM oocytes with regard to success of oocyte maturation as determined by presence of the polar body. The highest maturation rate was obtained in the TCM24aspiration group (79.8 $\pm 4.3 \%)$, followed by the group supplemented with cAMP modulators $(74.5 \pm 4.4 \%)$; and the TCM24slicing system $(70.1 \pm$ $3.6 \%$; mean \pm SEM (standard error of the mean); Table 4).

Statistical differences were observed in cleavage rates among treatments. The cAMP30aspiration protocol showed the highest cleavage rate $(70.1 \pm$ $2.4 \%)$, a result that differed significantly $(P<0.05)$ from that of TCM24slicing $(58.9 \pm 1.5 \%)$, whereas TCM24aspiration $(63.0 \pm 2.3 \%)$ did not differ significantly from either treatment. When blastocyst rates per presumptive zygote were calculated, the TCM24aspiration group showed a significantly $(P<$ $0.05)$ higher percentage $(32.2 \pm 2.1 \%)$ of development compared with TCM24slicing and cAMP30aspiration $(23.4 \pm 1.2 \%$ and $23.3 \pm 1.9 \%$, respectively; Table 3$)$. Embryos from the three in vitro treatments and in vivoproduced embryos were compared using differential staining. In contrast with the blastocyst rates, no statistical differences were found among the different sources of blastocysts with regard to cell numbers (Table 5).

\section{Gene expression analysis}

The expression levels for EGR1 were significantly lower $(P<0.05)$ in all groups of in vitro-produced embryos compared with the in vivo-produced blastocysts, whereas similar expression patterns were observed among the different in vitro protocols. The relative 
Table 5 Effect of oocyte retrieval method and maturation system on expanded blastocyst cell numbers

\begin{tabular}{lcrccc}
\hline Treatment & Total $(n)$ & Total cells & ICM & TE & ICM/Total cells (\%) \\
\hline TCM24slicing $^{a}$ & 10 & $129 \pm 5.0$ & $29.4 \pm 3.5$ & $100 \pm 5.0$ & $23.3 \pm 2.4$ \\
TCM24aspiration $^{a}$ & 16 & $132.2 \pm 4.0$ & $37.4 \pm 2.7$ & $95 \pm 4.0$ & $27.7 \pm 1.9$ \\
cAMP30aspiration $^{a}$ & 7 & $129 \pm 6.0$ & $34 \pm 4.2$ & $95 \pm 6.0$ & $26.8 \pm 2.9$ \\
In vivo $^{\text {a }}$ & 9 & $134.1 \pm 5.3$ & - & - & - \\
\hline
\end{tabular}

Data are expressed as mean \pm standard error of the mean (SEM). ICM, inner cell mass; TE, trophectoderm. ${ }^{a}$ Embryos from three different replicates were evaluated.

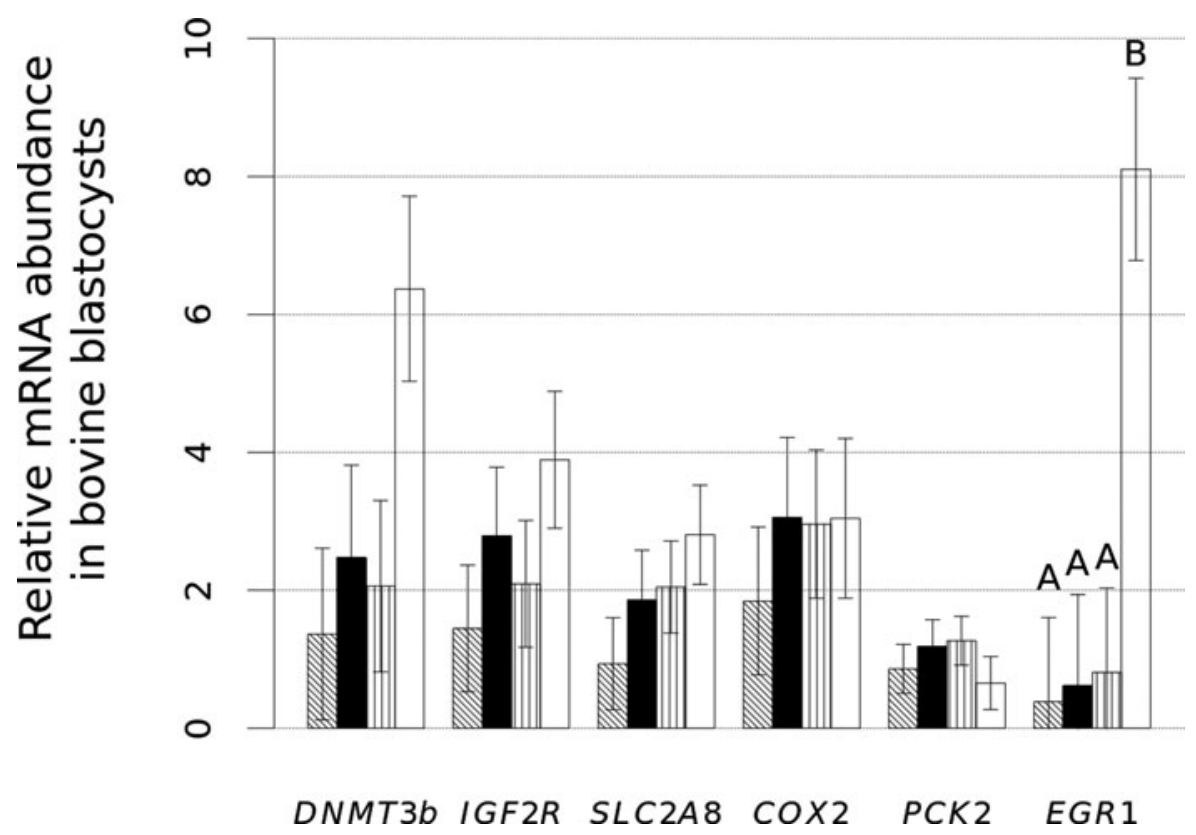

Figure 1 Effect of the oocyte in vitro maturation system on gene expression in day 8 expanded blastocysts compared with in vivo-produced embryos. Genes DNMT3b, IGF2R, SLC2A8, COX2, PCK2, EGR1 were analyzed. TCM24slicing (shaded), TCM24aspiration (black), cAMP30aspiration (vertically lined), in vivo (white). Normalized transcription levels are shown as mean \pm standard error of the mean (SEM). ${ }^{\mathrm{A}, \mathrm{B}}$ Different superscripts indicate statistical differences among treatment groups $(P<0.05)$. Data were obtained from seven replicates.

abundance of transcripts for DNMT3b, IGF2R and $S L C 2 A 8$ in embryos produced in vivo was not statistically different compared with controls. Similar mRNA expression profiles were observed in blastocysts from the four different sources for COX2 and PCK2 genes (Fig. 1).

\section{Analysis of DNA methylation}

The number of CpGs analysed and the mean percentages of methylated CpGs for each protocol and satellite are shown in Table 6. Embryos produced either by the SPOM-like system or in vivo generally showed a lower DNA methylation than embryos produced in the two other in vivo-produced groups. No statistical differences were found between TCM24slicing (30.5 \pm
$2.2 \%)$ and TCM24aspiration for BTS $(32.0 \pm 2.3 \%)$ and $\mathrm{BT} \alpha \mathrm{S}(49.1 \pm 2.3 \%$ and $52.7 \pm 3.0 \%$, respectively) while the DNA methylation in cAMP30aspiration and in vivo-produced embryos was significantly lower $(P<0.05)$ (Table 6). This finding indicates that in vitro-produced embryos derived without the extended maturation period and supplementation of cAMP modulators were hypermethylated at the CpG sites compared with embryos produced by the modified SPOM system (cAMP30aspiration) or in vivo embryos. Embryos produced in vivo and those from the cAMP30aspiration protocol showed significantly $(P<0.05)$ reduced methylation for the two satellites $(16.4 \pm 1.4 \%$ and $8.1 \pm 1.3 \%$ for BTS, and $40.1 \pm$ $.2 .1 \%$ and $32.2 \pm 2.5 \%$ for $\mathrm{BT} \alpha \mathrm{S}$, respectively), when compared with the other experimental groups (Table 6). 
Table 6 Number of CpGs evaluated and level of methylation in bovine expanded blastocysts

\begin{tabular}{|c|c|c|c|c|}
\hline Satellite & Protocol & $\begin{array}{c}\text { CpGs } \\
\text { evaluated }(n)\end{array}$ & $\begin{array}{l}\text { CpGs } \\
\text { methylated }(n)\end{array}$ & $\begin{array}{c}\text { Methylation } \\
\text { level (\%) }\end{array}$ \\
\hline \multirow[t]{4}{*}{ Bovine testis satellite I (BTS) } & TCM24slicing & 426 & 130 & $30.5 \pm 2.2^{A}$ \\
\hline & TCM24aspiration & 394 & 126 & $32.0 \pm 2.3^{A}$ \\
\hline & cAMP30aspiration & 404 & 33 & $8.1 \pm 1.3^{B}$ \\
\hline & In vivo & 620 & 102 & $16.4 \pm 1.4^{C}$ \\
\hline \multirow[t]{4}{*}{ Bos taurus alpha satellite I (BT $\alpha S)$} & TCM24 slicing & 442 & 217 & $49.1 \pm 2.3^{a}$ \\
\hline & TCM24aspiration & 271 & 143 & $52.7 \pm 3.0^{a}$ \\
\hline & cAMP30aspiration & 357 & 115 & $32.2 \pm 2.5^{b, c}$ \\
\hline & In vivo & 518 & 208 & $40.1 \pm 2.1^{c}$ \\
\hline
\end{tabular}

$A, B, C, a, b, c$ Rows with different superscript letters per satellite are significantly different $(P<0.05)$,

Data are expressed as mean \pm standard error of the mean (SEM).

\section{Discussion}

The current work investigated for the first time the effects of oocyte retrieval and IVM systems using cAMP modulators on the mRNA expression profiles of bovine blastocysts for one imprinted and four non-imprinted genes, and unravelled its effects on global DNA methylation dynamics represented by two satellite DNA repeat sequences. Furthermore, embryos derived from the SPOM maturation system were characterized with regard to mRNA expression and satellite DNA methylation profile.

In vitro oocyte maturation is critical for the acquisition of full developmental competence. To induce a more physiological maturation process, biphasic IVM protocols have been proposed, by combination of an initial inhibitory culture period, using various cAMP modulators, followed by the conventional IVM phase that included hormone supplementation (Downs et al., 1986; Hashimoto et al., 2002). Recently, Albuz et al. (2010) proposed the SPOM system that is based on a two-step protocol and includes cAMP modulators before and during IVM.

Total blastocyst cell number and, specifically, the allocation of cells to the ICM or trophectoderm (TE) are considered to be important criteria for the assessment of blastocyst quality (Mori et al., 2002; Ushijima et al., 2008; Velazquez et al., 2012). In contrast with that of Albuz et al. (2010), the present study did not reveal differences in total cell numbers and ICM/total cells ratio for CAMP modulators and extended maturationderived blastocysts. The figures were similar to those of in vivo-produced blastocysts, which are considered to be the standard control.

No increase in blastocyst production was observed in the current study, a finding that is in contrast with the values reported by Albuz et al. (2010) after an extended $(30 \mathrm{~h})$ maturation period in the presence of cilostamide. However, an increased percentage was obtained when oocytes were aspirated from follicles rather than collected by slicing and when COCs were maintained in follicular fluid followed by a conventional maturation protocol (TCM24aspiration). These observations could suggest that oocyte maintenance in follicular fluid during and after recovery is beneficial to oocyte competence, presumably related to the maintenance of the CAMP levels in the COCs, modulated by the follicular fluid. It has been also stated that not only cAMP, but also other pathways such as AMP-activated protein kinase, cGMP, and $\mathrm{Ca}^{2+}$ play a major role in the maintenance of meiotic inhibition (Bilodeau-Goeseels, 2011).

It has been shown that the use of several assisted reproductive technologies (ARTs), which include IVM, can affect gene expression and epigenetic marks in oocytes and embryos (Wrenzycki et al., 2005b, 2007; Niemann et al., 2010). With the exception of EGR1, no significant differences were observed in the current study with regard to mRNA expression levels of the selected developmentally important genes DNMT3b, IGF2R, SLC2A8, COX2, PCK2 between the different in vitro treatments and in vivo-derived blastocysts. This situation indicates that in vitro methods were compatible with physiological expression levels. However, significant down-regulation of EGR1 mRNA levels in all in vitro-produced blastocysts compared with their in vivo counterparts was discovered. EGR1 has previously been shown to be closely related to oocyte developmental competence; the expression level correlated with successful follicular maturation (Robert et al., 2001). The present study showed that expression in embryos produced in vivo was eightfold higher than for in vitro-produced embryos, which indicates that EGR1 mRNA expression could serve as a marker of embryo quality.

Two types of DNA methyltransferase (DNMT) activity have been described in vertebrates, related to de novo and maintenance of methylation levels. The current results, as previously reported in mice by Horii et al. (2011), showed slightly lower transcript 
levels for the de novo DNA methylation enzyme $D N M T 3 b$ in the in vitro - produced blastocysts in comparison with their in vivo-produced counterparts. A physiological expression level of COX2 has been related to successful pregnancy establishment and calf delivery, probably due to its crucial function in differentiation, proliferation and anti-apoptosis (Smith et al., 2000; El-Sayed et al., 2006; Pakrasi \& Jain, 2008). In the current study, it was observed that COX2 expression profiles were closer to that of in vivo-produced embryos in the IVM protocols using aspiration rather than retrieval method. The imprinted IGF2R gene is critically involved in the control of fetal growth by acting as a scavenger receptor for the imprinted fetal mitogen insulinlike growth factor (IGF; Suteevun-Phermthai et al., 2009). Moore et al. (2007) reported a higher level mRNA expression pattern for IGF2R in embryos produced in vivo compared with in vitro embryos. The relative abundance of solute carrier family 2 (facilitated glucose transporter) member 8 transcripts was decreased in all in vitro-produced blastocysts. It has been reported that murine blastocysts that lack SLC2A8 expression showed increased apoptosis levels, a finding that suggested a critical role in embryonic development and survival (Pinto et al., 2002). In contrast with the other genes evaluated in the present study, the mRNA level of the PCK2 gene, which is involved in glucose metabolism, tended to be upregulated in embryos produced in vitro over their in vivo-produced counterparts.

Epigenetic processes such as DNA methylation and histone modifications have been shown to be heavily affected by ARTs (Niemann et al., 2010). It has been stated that alterations in methylation patterns can lead to severe imprinting errors (Katari et al., 2009; Wilkins-Haug, 2009), such as BeckwithWiedeman syndrome (Paoloni-Giacobino, 2007) in humans or the large offspring syndrome in cattle (Farin et al., 2006). In oocytes and early embryos, the effects of in vitro procedures are also reflected in distinct mRNA expression profiles (Wrenzycki et al., 2005a; Farin et al., 2010; Heinzmann et al., 2011; Diederich et al., 2012). Accordingly, many studies have argued that ARTs can induce aberrant DNA methylation patterns in preimplantation embryos (Wrenzycki et al., 2005a; Paoloni-Giacobino, 2007; Sawai et al., 2011). In the current study, two satellite regions, the bovine testis satellite I (BTS) and the Bos taurus alpha satellite I (BT $\alpha S)$, were studied to evaluate global methylation profiles that are representative of the bovine genome (Kang et al., 2005). The current results revealed significant hypermethylation for both satellite sequences in embryos derived from treatments that lack cAMP modulators in comparison with their in vivo-derived counterparts. Increased
DNA methylation levels of BTS have been reported previously for embryos produced in vitro (Sawai et al., 2011; Yamanaka et al., 2011). In contrast, in the current study, similar profiles of DNA methylation for both satellite regions were observed in blastocysts produced in vivo or in vitro with cAMP modulators. These results could suggest that the embryos produced using the cAMP modulators forskolin, IBMX and cilostamide along with an extended IVM are similar to their in vivo-produced counterparts that usually serve as the physiological standard. This situation indicates that the global methylation profile of blastocysts can be influenced significantly by in vitro maturation conditions.

In conclusion, the present results suggest that epigenetic processes during embryo development are influenced by IVM protocols and oocyte retrieval system and that the addition of cAMP modulators in conjunction with an extended IVM may have a positive influence on embryo quality, probably associated with sustained levels of cAMP in oocytes and the surrounding cells. This situation is important to gain a better understanding of the SPOM system, which has been shown to be compatible with high blastocyst rates. The current findings highlight the need to continue the search for media and protocols that provide a physiological environment for the oocyte under in vitro conditions. In this context, the bovine species can serve as a useful model for human IVM due to the high degree of similarity in human and bovine embryo development.

\section{Acknowledgements}

The authors would like to thank Patrick Aldag, Brigitte Barg-Kues and Klaus-Gerd Hadeler for excellent technical support in the laboratory as well as in the cow barn.

This research was supported in part by the DFG Research Group 'Germ Cell Potential' (FOR1041). S. Bernal was supported by The Netherlands Fellowship Programmes (NFP) of the Nuffic Foundation.

\section{Conflict of interest}

The authors declare that there is no conflict of interest that could be perceived as prejudicing the impartiality of the research reported.

\section{References}

Albuz, F.K., Sasseville, M., Lane, M., Armstrong, D.T., Thompson, J.G. \& Gilchrist, R.B. (2010). Simulated physiological oocyte maturation (SPOM): a novel in vitro maturation system that substantially improves embryo yield and pregnancy outcomes. Hum. Reprod. 25, 29993011. 
Bilodeau-Goeseels, S. (2011). Cows are not mice: the role of cyclic AMP, phosphodiesterases, and adenosine monophosphate-activated protein kinase in the maintenance of meiotic arrest in bovine oocytes. Mol. Reprod. Dev. 78, 734-43.

Bock, C., Reither, S., Mikeska, T., Paulsen, M., Walter, J. \& Lengauer, T. (2005). BiQ Analyzer: visualization and quality control for DNA methylation data from bisulfite sequencing. Bioinformatics 21, 4067-8.

Bungartz, L. \& Niemann, H. (1994). Assessment of the presence of a dominant follicle and selection of dairy cows suitable for superovulation by a single ultrasound examination. J. Reprod. Fertil. 101, 583-91.

Cheng, J.F., Raid, L. \& Hardison, R.C. (1986). Isolation and nucleotide sequence of the rabbit globin gene cluster $\psi \xi$ $\alpha 1-\psi \alpha$. Absence of a pair of $\alpha$-globin genes evolving in concert. J. Biol. Chem. 261, 84-938.

Diederich, M., Hansmann, T., Heinzmann, J., Barg-Kues, B., Herrmann, D., Aldag, P., Baulain, U., Reinhard, R., Kues, W., Weissgerber, C., Haaf, T. \& Niemann, H. (2012). DNA methylation and mRNA expression profiles in bovine oocytes derived from prepubertal and adult donors. Reproduction 144, 319-30.

Downs, S.M., Schroeder, A.C. \& Eppig, J.J. (1986). Developmental capacity of mouse oocytes following maintenance of meiotic arrest in vitro. Gamete Res. 15, 305-16.

Eckert, J. \& Niemann, H. (1995). In vitro maturation, fertilization and culture to blastocysts of bovine oocytes in protein-free media. Theriogenology 43, 1211-25.

El-Sayed, A., Hoelker, M., Rings, F., Salilew, D., Jennen, D., Tholen, E., Sirard, M. A., Schellander, K. \& Tesfaye, D. (2006). Large-scale transcriptional analysis of bovine embryo biopsies in relation to pregnancy success after transfer to recipients. Physiol. Genomics 28, 8496.

Farin, P.W., Piedrahita, J.A. \& Farin, C.E. (2006). Errors in development of fetuses and placentas from in vitroproduced bovine embryos. Theriogenology 65, 178-91.

Farin, C.E., Alexander, J.E. \& Farin, P.W. (2010). Expression of messenger RNAs for insulin-like growth factors and their receptors in bovine fetuses at early gestation from embryos produced in vivo or in vitro. Theriogenology 74, 1288-95.

Goodhand, K.L., Watt, R.G., Staines, M.E., Hutchinson, J.S.M. \& Broadbent, P.J. (1999). In vivo oocyte recovery and in vitro embryo production from bovine donors aspirated at different frequencies or following FSH treatment. Theriogenology 51, 951-61.

Hashimoto, S., Minami, N., Takakura, R. \& Imai, H. (2002). Bovine immature oocytes acquire developmental competence during meiotic arrest in vitro. Biol. Reprod. 66, 1696-701.

Heinzmann, J., Hansmann, T., Herrmann, D., Wrenzycki, C., Zechner, U., Haaf, T. \& Niemann, H. (2011). Epigenetic profile of developmentally important genes in bovine oocytes. Mol. Reprod. Dev. 78, 188-201.

Holker, M., Petersen, B., Hassel, P., Kues, W.A., Lemme, E., Lucas-Hahn, A. \& Niemann, H. (2005). Duration of in vitro maturation of recipient oocytes affects blastocyst development of cloned porcine embryos. Cloning Stem Cells 7, 35-44.
Horii, T., Suetake, I., Yanagisawa, E., Morita, S., Kimura, M., Nagao, Y., Imai, H., Tajima, S. \& Hatada, I. (2011). The Dnmt3b splice variant is specifically expressed in in vitromanipulated blastocysts and their derivative ES cells. J. Reprod. Develop. 57, 579-85.

Kang, Y.K., Koo, D.B., Park, J.S., Choi, Y.H., Chung, A.S., Lee, K.K. \& Han, Y.M. (2001). Aberrant methylation of donor genome in cloned bovine embryos. Nat. Genet. 28, 173-7.

Kang, Y.K., Lee, H.J., Shim, J.J., Yeo, S., Kim, S.H., Koo, D.B., Lee, K.K., Beyhan, Z., First, N.L. \& Han, Y.M. (2005). Varied patterns of DNA methylation change between different satellite regions in bovine preimplantation development. Mol. Reprod. Dev. 71, 29-35.

Katari, S., Turan, N., Bibikova, M., Erinle, O., Chalian, R., Foster, M., Gaughan, J.P., Coutifaris, C. \& Sapienza, C. (2009). DNA methylation and gene expression differences in children conceived in vitro or in vivo. Hum. Mol. Genet. 18, 3769-78.

Looney, C.R., Lindsey, B.R., Gonseth, C.L. \& Johnson, D.L. (1994). Commercial aspects of oocyte retrieval and in-vitro fertilization (IVF) for embryo production in problem cows. Theriogenology 41, 67-72.

Mehlmann, L.M. (2005). Stops and starts in mammalian oocytes: recent advances in understanding the regulation of meiotic arrest and oocyte maturation. Reproduction 130, 791-9.

Moore, K., Kramer, J.M., Rodriguez-Sallaberry, C.J., Yelich, J.V. \& Drost, M. (2007). Insulin-like growth factor (IGF) family genes are aberrantly expressed in bovine conceptuses produced in vitro or by nuclear transfer. Theriogenology 68, 717-27.

Mori, M., Otoi, T. \& Suzuki, T. (2002). Correlation between the cell number and diameter in bovine embryos produced in vitro. Reprod. Domest. Anim. 37, 181-4.

Niemann, H., Carnwath, J. W., Herrmann, D., Wieczorek, G., Lemme, E., Lucas-Hahn, A. \& Olek, S. (2010). DNA methylation patterns reflect epigenetic reprogramming in bovine embryos. Cell Reprogram. 12, 33-42.

Pakrasi, P.L. \& Jain, A.K. (2008). Cyclooxygenase-2-derived endogenous prostacyclin reduces apoptosis and enhances embryo viability in mouse. Prostaglandins Leukot. Essent. Fatty Acids 79, 27-33.

Paoloni-Giacobino, A. (2007). Epigenetics in reproductive medicine. Pediatr. Res. 61, 51R-7R.

Parrish, J.J., Susko-Parrish, J.L., Leibfried-Rutledge, M.L., Critser, E.S., Eyestone, W.H. \& First, N.L. (1986). Bovine in vitro fertilization with frozen-thawed semen. Theriogenology 25, 591-600.

Parrish, J.J., Susko-Parrish, J., Winer, M.A. \& First, N.L. (1988). Capacitation of bovine sperm by heparin. Biol. Reprod. 38, 1171-1180.

Pincus, G. \& Enzmann, E. V. (1935). The comparative behavior of mammalian eggs in vivo and in vitro: I. the activation of ovarian eggs. J. Exp. Med. 62, 665-75.

Pinto, A.B., Carayannopoulos, M.O., Hoehn, A., Dowd, L. \& Moley, K.H. (2002). Glucose transporter 8 expression and translocation are critical for murine blastocyst survival. Biol. Reprod. 66, 1729-33.

Robert, C., Gagne, D., Bousquet, D., Barnes, F.L. \& Sirard, M.A. (2001). Differential display and suppressive subtractive hybridization used to identify granulosa 
cell messenger RNA associated with bovine oocyte developmental competence. Biol. Reprod. 64, 1812-20.

Sawai, K., Takahashi, M., Fujii, T., Moriyasu, S., Hirayama, H., Minamihashi, A., Hashizume, T. \& Onoe, S. (2011). DNA methylation status of bovine blastocyst embryos obtained from various procedures. J. Reprod. Dev. 57, 23641.

Smith, W.L., DeWitt, D.L. \& Garavito, R.M. (2000). Cyclooxygenases: structural, cellular, and molecular biology. Ann. Rev. Biochem. 69, 145-82.

Stroud, B. (2012). IETS 2012 Statistics and Data Retrieval Committee Report. The year 2012 worldwide statistics of embryo transfer in domestic farm animals. IETS Newsletter 30, 16-26.

Suteevun-Phermthai, T., Curchoe, C.L., Evans, A.C., Boland, E., Rizos, D., Fair, T., Duffy, P., Sung, L.Y., Du, F., Chaubal, S., Xu, J., Wechayant, T., Yang, X., Lonergan, P., Parnpai, R. \& Tian, X.C. (2009). Allelic switching of the imprinted IGF2R gene in cloned bovine fetuses and calves. Anim. Reprod. Sci. 116, $19-27$.

Thouas, G.A., Korfiatis, N.A., French, A.J., Jones, G.M. \& Trounson, A.O. (2001). Simplified technique for differential staining of inner cell mass and trophectoderm cells of mouse and bovine blastocysts. Reprod. Biomed. Online 3, 25-9.

Tripathi, A., Kumar, K.V. \& Chaube, S.K. (2010). Meiotic cell cycle arrest in mammalian oocytes. J. Cell Physiol. 223, 592600.

Tsafriri, A. \& Pomerantz, S.H. (1986). Oocyte maturation inhibitor. Clin. Endocrinol. Metab 15, 157-70.

Ushijima, H., Akiyama, K. \& Tajima, T. (2008). Transition of cell numbers in bovine preimplantation embryos: in vivo collected and in vitro produced embryos. J. Reprod. Dev. 54, 239-43.
Velazquez, M.A., Hadeler, K.G., Herrmann, D., Kues, W.A., Remy, B., Beckers, J.F. \& Niemann, H. (2012). In vivo oocyte IGF-1 priming increases inner cell mass proliferation of in vitro-formed bovine blastocysts. Theriogenology 78, 517-27.

Wilkins-Haug, L. (2009). Epigenetics and assisted reproduction. Curr. Opin. Obstet. Gynecol. 21, 201-6.

Wrenzycki, C., Herrmann, D., Keskintepe, L., Martins, A., Jr., Sirisathien, S., Brackett, B. \& Niemann, H. (2001). Effects of culture system and protein supplementation on mRNA expression in pre-implantation bovine embryos. Hum. Reprod. 16, 893-901.

Wrenzycki, C., Herrmann, D., Lucas-Hahn, A., Gebert, C., Korsawe, K., Lemme, E., Carnwath, J.W. \& Niemann, H. (2005a). Epigenetic reprogramming throughout preimplantation development and consequences for assisted reproductive technologies. Birth Defects Res. C Embryo. Today 75, 1-9.

Wrenzycki, C., Herrmann, D., Lucas-Hahn, A., Korsawe, K., Lemme, E. \& Niemann, H. (2005b). Messenger RNA expression patterns in bovine embryos derived from in vitro procedures and their implications for development. Reprod. Fertil. Dev. 17, 23-35.

Wrenzycki, C., Herrmann, D. \& Niemann, H. (2007). Messenger RNA in oocytes and embryos in relation to embryo viability. Theriogenology 68 Suppl 1, S77-83.

Yamanaka, K., Kaneda, M., Inaba, Y., Saito, K., Kubota, K., Sakatani, M., Sugimura, S., Imai, K., Watanabe, S. \& Takahashi, M. (2011). DNA methylation analysis on satellite I region in blastocysts obtained from somatic cell cloned cattle. Anim. Sci. J. 82, 523-30.

Zhang, M., Su, Y.Q., Sugiura, K., Xia, G. \& Eppig, J.J. (2010). Granulosa cell ligand NPPC and its receptor NPR2 maintain meiotic arrest in mouse oocytes. Science 330, 3669. 